\title{
Valor prognóstico da variabilidade da frequência cardíaca e da eletrocardiografia ambulatorial em cães Boxer com cardiomiopatia arritmogênica do ventrículo direito
}

\author{
[Prognostic value of heart rate variability and Holter monitoring in Boxer dogs with \\ arrhythmogenic right ventricular cardiomyopathy] \\ P.P.C. Chamas, V.M.C. Oliveira, F.L. Yamaki, G.T. Goldfeder, M.H.M.A. Larsson
}

Faculdade de Medicina Veterinária - Universidade de São Paulo - USP - São Caetano do Sul, SP

\section{RESUMO}

A cardiomiopatia arritmogênica do ventrículo direito (CAVD) é uma importante causa de morte súbita em cães da raça Boxer. A validação de fatores prognósticos para essa doença auxiliaria na detecção de animais mais gravemente afetados e sua exclusão dos programas de reprodução. $\mathrm{O}$ objetivo deste estudo foi avaliar o valor prognóstico da presença de manifestações clínicas, dos índices de variabilidade de frequência cardíaca (VFC) e das arritmias supraventriculares ou ventriculares registradas à monitorização eletrocardiográfica com Holter na sobrevida de cães Boxer em diferentes estágios da CAVD. Essas variáveis foram analisadas, de forma prospectiva, em 69 cães Boxer, divididos em cinco grupos: cães Boxer controle (grupo CB, <50 VPC/24 horas, $\mathrm{n}=28$ ), cães Boxer suspeitos (grupo SB, 50 a $300 \mathrm{VPC} / 24$ horas, $\mathrm{n}=8$ ), cães Boxer com CAVD (grupo ARVC, $>300$ VPC/24 horas, $n=19$ ), cães Boxer com CAVD e disfunção sistólica sem insuficiência cardíaca congestiva (grupo SDB sem ICC, n=6) e com ICC (grupo SDB com ICC, n=8). A análise estatística compreendeu teste ANOVA, correlação de Pearson e análise de riscos proporcionais de Cox. Comparando-se com o grupo CB, não foi encontrada diminuição nos índices de VFC nos grupos SB, ARVC ou SDB sem ICC; por outro lado, o grupo SDB com ICC apresentou diminuição desses índices. Não houve relação entre os índices de VFC e a morte de origem cardíaca; porém, a presença de síncopes com ou sem sinais clínicos de ICC e o número de episódios de taquicardia ventricular (TV) correlacionaram-se com a sobrevida dos animais. Estes resultados permitem concluir que a presença de sinais clínicos de ICC, a presença de síncopes e o número de TV ao Holter apresentam valor prognóstico de sobrevida em cães Boxer com CAVD.

Palavras-chave: cães Boxer, cardiomiopatia arritmogênica, sistema nervoso autônomo, taquicardia ventricular

\begin{abstract}
Arrhythmogenic right ventricular cardiomyopathy (ARVC) is an important cause of sudden death in Boxer dogs. Validation of prognostic factors for this disease could help in detecting more severely affected animals and their exclusion from breeding programs. The aims of this study were to evaluate the prognostic significance of presence of symptoms, heart rate variability (HRV) indices and ventricular or supraventricular arrhythmias recorded by Holter monitoring on survival of Boxer dogs with ARVC at different stages. Symptoms, arrhythmias registered on Holter and five HRV indices were prospectively analyzed in 69 clientowned Boxer dogs divided into five groups: control Boxer dogs (CB group, $<50$ VPC/24 hours, $n=28$ ), suspicious Boxers (SB group, 50 to $300 \mathrm{VPC} / 24$ hours, $n=8$ ), Boxers with ARVC (ARVC group, >300 VPC/24 hours, $n=19$ ), Boxers with ARVC and systolic dysfunction without congestive heart failure (SDB without CHF group, $n=6)$ and with CHF (SDB with CHF group, $n=8$ ). Statistical analyses consisted of an ANOVA test, Pearson correlation and Cox's proportional hazards regression. Compared to the CB group, no decrease in $H R V$ indices was found in SB, ARVCB or SDB without CHF groups; otherwise, SDB with CHF group had impaired indices. No relation was found between HRV indices and cardiac-related death, but the presence of syncopes with or without clinical signs of heart failure and number of ventricular tachycardia (VT), were correlated with survival. These results allow us to conclude that the presence of symptoms of heart failure, presence of syncopes and number of VT on Holter examination seem to have prognostic value in Boxer ARVC.
\end{abstract}

Keywords: Boxer dogs, arrhythmogenic cardiomyopathy, autonomic nervous system, ventricular tachycardia

Recebido em 20 de abril de 2015

Aceito em 18 de fevereiro de 2016

E-mail: pchamas@yahoo.com.br 


\section{INTRODUCTION}

Boxer arrhythmogenic right ventricular cardiomyopathy (ARVC) is a myocardial disease with familial occurrence with an autosomal dominant inheritance pattern (Meurs et al., 1999, Basso et al., 2004). It is caused by mutations in genes encoding the adhesion proteins of desmosomes in cardiomyocytes, which is followed by consequent detachment, apoptosis and replacement of cells by fibrofatty tissues, which provides a substrate for the genesis of ventricular reentry arrhythmias (Meurs et al., 2007; Oxford et al., 2007; Meurs et al., 2010; Oxford et al., 2011). Because of variable genetic penetrance, affected animals may manifest different forms of the disease. Thus, a dog may present subclinical disease or present with syncope or sudden death as a result of ventricular arrhythmias. More rarely, these dogs may present with signs of congestive heart failure due to systolic dysfunction and biventricular dilation that mimic idiopathic dilated cardiomyopathy; supraventricular tachyarrhythmias, such as atrial fibrillation, are also possible in these dogs (Harpster, 1983; Bright and McEntee, 1995; Moïse, 1999; Sisson et al., 1999; Corrado et al. 2000; Meurs, 2004; Basso et al., 2004; Baumwart et al., 2005). Although most reports affirm that this type of Boxer ARVC is diagnosed less frequently, a European study found a higher incidence of this form of the disease (Palermo et al., 2011).

The evaluation of heart rate variability (HRV) can be used to observe the influence of the autonomic nervous system on the heart. It can be evaluated by time domain or frequency domain analysis; in time domain analysis, every RR interval is measured in a period of time, and the indices showing the fluctuation that occurs during the cardiac cycle are then calculated. Reduction in HRV is considered a predictor of death from heart failure or sudden death from ventricular arrhythmias in humans (Malik et al., 1996). A study conducted to assess HRV in human ARVC found that the decreased values of these indices in patients affected with the most severe form of the disease were associated with poor prognosis (Folino et al., 2002). Temporal variability of ventricular arrhythmias in Boxer dogs with ARVC was studied and revealed a slight rise in prevalence of these ectopies in some hours of the day, suggesting a circadian influence of the autonomic activity in the modulation of electrical instability in these dogs (Scansen et al., 2009). Heart rate variability has also been evaluated in Boxer dogs with ARVC to examine the possibility of persistently high sympathetic tone in the genesis of ventricular arrhythmias among affected animals, and the authors have found little or no decrease in the HRV indices of affected animals without congestive heart failure (Spier and Meurs 2004a).

The aim of this study was to assess the prognostic value of the following variables for the occurrence of death of cardiac origin (sudden death or death from congestive heart failure) in Boxer dogs with ARVC: age, sex, weight, symptoms, HRV indices and ventricular or supraventricular arrhythmias registered on Holter monitoring.

\section{MATERIAL AND METHODS}

Sixty-nine Boxer dogs presented to the Cardiology Service of the Veterinary Hospital of São Paulo University were recruited for this study. These animals were screened by physical examination, laboratory panels $(\mathrm{CBC}$, hepatic and renal function, and sodium and potassium levels), indirect measurement of arterial blood pressure, thoracic radiography, electrocardiography (2-minutes ECG), echocardiography and ambulatory electrocardiography (twenty-four hour Holter monitoring). The exclusion criteria was the presence of malignant neoplasias, systemic diseases, congenital heart diseases, significant valvular disease and laboratory abnormalities that could lead to ventricular arrhythmias.

The selected animals were placed in the following five different groups according to the number of ventricular extrasystoles on Holter monitoring and the echocardiography results:

- CB (control Boxer) group, consisting of 28 apparently healthy Boxer dogs with low numbers (less than 50) of VPCs in the 24 hour ambulatory electrocardiography;

- SB (suspicious Boxer) group, consisting of 8 Boxer dogs with 50 to 300 VPCs on Holter examination, that could be neither diagnosed nor excluded based upon this examination and thus were considered equivocal for ARVC; 


\begin{abstract}
- ARVCB (arrhythmogenic right ventricular cardiomyopathy Boxer) group, consisting of 19 Boxer dogs with more than 300 VPCs on Holter examination and normal results on echocardiography; these dogs were considered affected by ARVC;
\end{abstract}

- SDB (systolic dysfunction Boxer) group, consisting of 14 ARVC Boxer dogs with frequent ventricular arrhythmias $(>300 \mathrm{VPC} / 24$ hour), as well as occasional supraventricular arrhythmias on Holter examination and left ventricular dilation and systolic dysfunction on echocardiography. To classify the dogs into this category, the systolic and diastolic diameter of the left ventricle, the left atrial diameter, the fractional shortening and the E-septum distance of the mitral valve were evaluated, and the guidelines proposed by Dukes-McEwan et al. (2003) were applied for the diagnosis of canine idiopathic dilated cardiomyopathy. Based on the measurements above, the animals of the study that exhibited at least one major criterion (left ventricular diastolic or systolic diameter exceeding the reference values established for the breed, shortening fraction or ejection fraction values below the reference values) plus three minor criteria (increased E-septum distance, enlarged left atrium, atrial fibrillation or ventricular arrhythmias) were diagnosed as having this disease. The echocardiographic values described by Schober et al. (2002) for healthy Boxer dogs were used as reference values (left ventricle diastolic diameter (LVDd) $3.41-5.29 \mathrm{~cm}$; left ventricle systolic diameter (LVDs) $2.25-3.69 \mathrm{~cm}$; left atrium/aorta (LA/Ao) ratio 1.06-2.06; fractional shortening (FS) 2044\%; mitral valve E-point to septal separation (EPSS) $0.12-0.72 \mathrm{~cm}$ ). The animals in this group were divided into two subgroups: the systolic dysfunction Boxer group without congestive heart failure (SDB without CHF, $\mathrm{n}=6$ ) and the systolic dysfunction Boxer group with congestive heart failure (SDB with $\mathbf{C H F}, \mathrm{n}=8$ ), according to absence or presence of clinical manifestations of congestive heart failure, such as ascites, pleural effusion or pulmonary edema. Initially in the study, there were 12 animals in the SDB with CHF group, but four of these dogs were excluded because they showed atrial fibrillation as the basal cardiac rhythm, which precludes heart rate variability analysis.
Twenty-four hour ambulatory electrocardiography was conducted with the dogs using a digital device (DMS model 300-7) that recorded information on an electromagnetic card. The recorded data were analyzed using a software analysis algorithm (CardioScan 12 system DMS Brazil) with continuous interactions by a trained veterinary cardiologist. Recordings consisting of less than 22 hours of data and those with atrial fibrillation as the basal cardiac rhythm were excluded. The time domain HRV indices that were obtained and analyzed included the following:

- SDNN (ms) -standard deviation of the NN intervals (normal-normal intervals between consecutive R-R waves of the sinus rhythm) in 24 hours;

- SDANN (ms) - standard deviation of the average NN interval calculated over short periods (5 minutes);

- SDNNi (index - ms) - mean of the 5-minute standard deviation of the NN interval calculated over 24 hours;

- rMSSD (ms) - square root of the mean squared differences of successive NN intervals examined;

- pNN50 (\%) - percentage of adjacent NN intervals differing by more than 50 milliseconds in duration.

The SDNN, SDANN and SDNNi indices are obtained from long-term records and represent the sympathetic and parasympathetic activity, but can not distinguish between changes in HRV that occur by increased sympathetic activity from those that occur by withdrawal of vagal tonus. Differently, the rMSSD and pNN50 indices represent parasympathetic activity, as these are calculated from the analysis of adjacent RR intervals (Vanderlei et al., 2009).

At the time of data acquisition, none of the animals studied was receiving antiarrhythmic medications, but after the data acquisition some of them received antiarrhythmic medications (amiodarone) and those in CHF also received other drugs, such as enalapril and furosemide. The causes of death were defined as cardiac or non-cardiac. Deaths of cardiac origin consisted of sudden cardiac death or death from CHF 
secondary to pulmonary edema or pleural effusion. Sudden cardiac death was defined as an unexpected natural death without apparent clinical signs during the preceeding 24-hour period. None of the animals in this study was euthanized. The duration of this study was 48 months; time of data acquisition was considered the starting point and cardiac death the end point for survival analysis. Dogs that died for other reasons, were alive at the end of the study, or were lost to follow-up were right-censored.

For statistical evaluation, analysis of variance (ANOVA) was used to investigate the differences in the mean values of the HRV indices among the different groups; the statistical significance of these results was confirmed by Dunnett's multiple comparison test. The Gaussian distribution of the sample was confirmed by D'Agostino-Pearson omnibus normality test. Pearson correlation coefficients were used to measure the degree and direction of correlation of HRV indices and the supraventricular (number of isolated APC) and ventricular arrhythmias (number of isolated VPC, paired VPC, ventricular bigeminism or non-sustained ventricular tachycardia) that were recorded by Holter monitoring. Sustained ventricular tachycardia was not evaluated because just one animal had this type of arrhythmia, while all of the others showed only non-sustained ventricular tachycardia. The variables of age, sex, weight, symptoms (exercise intolerance, presence of syncope and clinical signs of heart failure), HRV indices, supraventricular arrhythmias and ventricular arrhythmias were also submitted to the Cox proportional hazards model for univariate and multivariate analyses to investigate the factors potentially associated with cardiovascular death. The Cox analysis was performed considering 66 animals, once 3 dogs were missing follow-up. Variables of biological importance or those found to be significant in univariate analyses were selectively included in the multivariate model. The Kaplan-Meier method was used to compute the overall survival time and to construct category-specific survival curves from the univariate analysis. Significance was defined as $\mathrm{P}<0.05$.

The present research agreed with the Ethical Principles in Animal Research adopted by the Bioethics Commission of the School of Veterinary Medicine of University of São Paulo (protocol number 1184/2007).

\section{RESULTS}

Initially, 87 animals were evaluated, but 18 were excluded from the study: nine because they had unacceptable Holter records (insufficient duration of recording or records of poor quality), five because they had concurrent diseases diagnosed after the screening tests (anemia, splenic node, lymph node enlargement and heart tumor) and four because they showed atrial fibrillation as the basal cardiac rhythm, precluding the analysis of heart rate variability.

According to the results of ambulatory electrocardiography and echocardiography, these 69 animals were divided into five groups. Among Boxer dogs with ARVC (ARVCB and SDB groups, $n=33$ ) that had experienced cardiac death $(n=20), 14$ had sudden cardiac death and death was caused by CHF in six. None of the animals in this study were euthanized. For the animals with sudden cardiac death, the mean survival time was $13.18 \pm 11.0$ months (range 1 to 22), and for animals that died from $\mathrm{CHF}$, the mean survival time was $5.33 \pm 5.13$ months (range 1 to 15 ). Although the survival rate was higher in those animals that had sudden death than those who died from $\mathrm{CHF}$, no significant differences were found between these two groups (Figure 1).

A Kaplan-Meier survival curve of the studied groups (Figure 2) demonstrated that there were no deaths of cardiac origin in the $\mathrm{CB}$ or $\mathrm{SB}$ groups. Conversely, in the ARVCB group, the probability of surviving more than 30 months was only $40 \%$. In the SDB group, almost all animals died (death of cardiac origin) within 18 months 


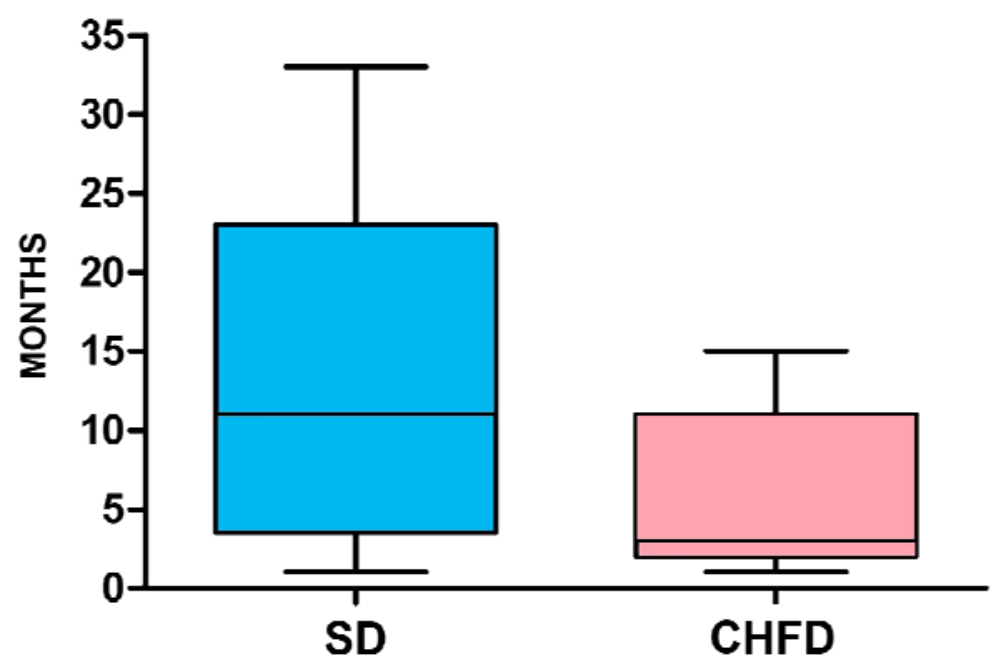

Figure 1. Survival time of Boxer dogs with ARVC $(n=20)$ that experienced sudden death $(S D, n=14)$ or death from congestive heart failure $(\mathrm{CHFD}, \mathrm{n}=6)(\mathrm{P}=0,1167)$.

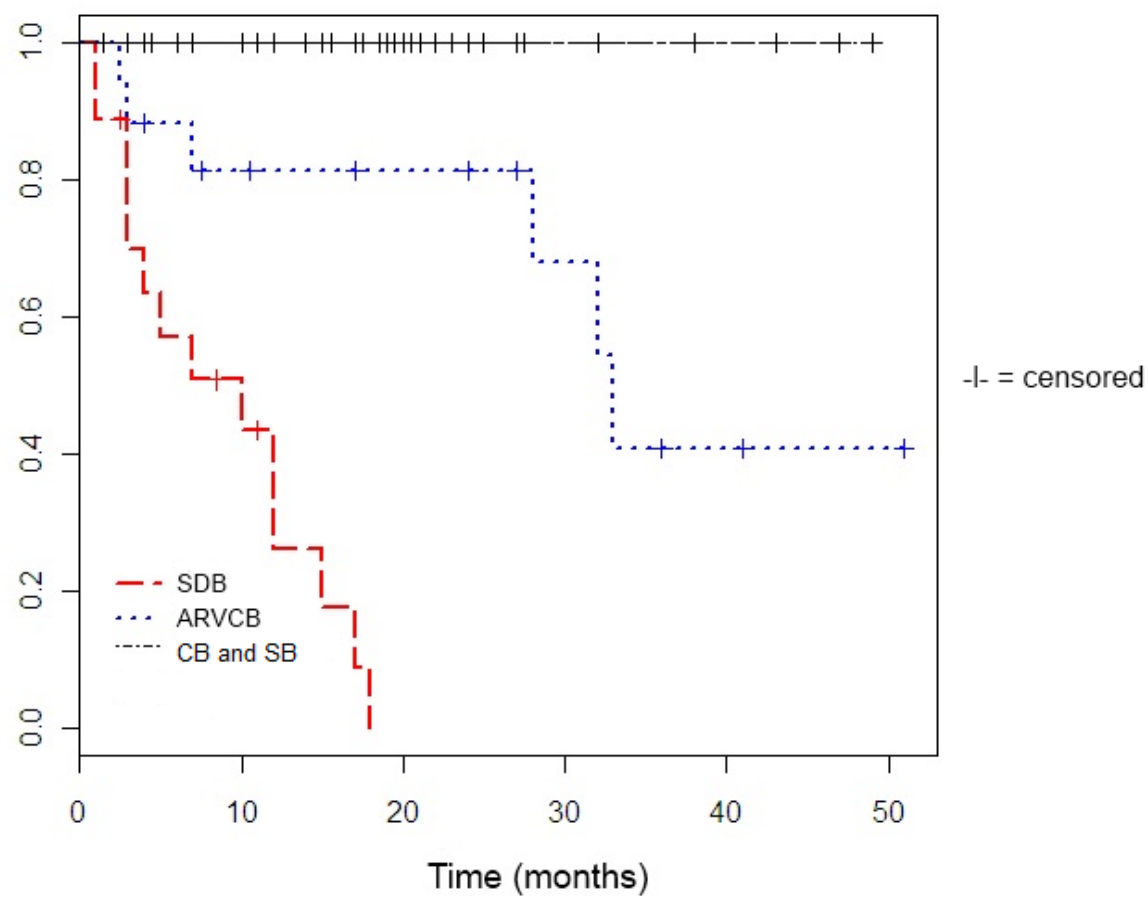

Figure 2. Kaplan-Meier estimate of survival of studied dogs, divided into four groups: CB - control Boxer dogs, SB - suspicious Boxer dogs, ARVCB - arrhythmogenic right ventricular cardiomyopathy Boxer dogs and SDB - systolic dysfunction Boxer dogs.

The results for the HRV indices (mean values \pm SD) of the five groups studied are given below (Table 1). No significant differences were found between the HRV indices of the CB group and the SB, ARVCB or SDB without CHF groups; however, a statistically significant difference between the $\mathrm{CB}$ and the SDB with CHF group $(p<0.05)$ was noted in all parameters of HRV. 
Table 1. Heart rate variability indices (mean values $\pm \mathrm{SD}$ ) in Boxer control dogs (CB group, $\mathrm{n}=28$ ), suspicious Boxer dogs (SB group, $\mathrm{n}=8$ ), arrhythmogenic right ventricular cardiomyopathy Boxer dogs (ARVC group, $\mathrm{n}=19$ ), systolic dysfunction Boxer dogs without cardiac heart failure (SDB without CHF, $\mathrm{n}=6$ ) and systolic dysfunction Boxer dogs with cardiac heart failure (SDB with CHF, $\mathrm{n}=8$ )

\begin{tabular}{c|c|c|c|c|c}
\hline Index & SDNN $(\mathrm{ms})$ & SDANN $(\mathrm{ms})$ & SDNNi $(\mathrm{ms})$ & rMSSD $(\mathrm{ms})$ & $\mathrm{pNN50}(\%)$ \\
\hline CB group & $122.82 \pm 41.92 \mathrm{a}$ & $108.79 \pm 45.0 \mathrm{a}$ & $78.43 \pm 16.65 \mathrm{a}$ & $44.43 \pm 8.59 \mathrm{a}$ & $17.75 \pm 4.97 \mathrm{a}$ \\
\hline SB group & $111.38 \pm 24.94 \mathrm{a}$ & $91.63 \pm 43.61 \mathrm{a}$ & $71.13 \pm 17.72 \mathrm{a}$ & $40.0 \pm 8.09 \mathrm{a}$ & $16.0 \pm 6.41 \mathrm{a}$ \\
\hline ARVC group & $99.11 \pm 16.41 \mathrm{a}$ & $80.68 \pm 28.11 \mathrm{a}$ & $63.63 \pm 10.64 \mathrm{a}$ & $39.0 \pm 7.79 \mathrm{a}$ & $15.63 \pm 6.78 \mathrm{a}$ \\
\hline $\begin{array}{c}\text { SDB without } \\
\text { CHF }\end{array}$ & $108.83 \pm 23.7 \mathrm{a}$ & $84.0 \pm 30.21 \mathrm{a}, \mathrm{b}$ & $65.67 \pm 13.88 \mathrm{a}, \mathrm{b}$ & $45.5 \pm 6.38 \mathrm{a}$ & $20.0 \pm 5.9 \mathrm{a}$ \\
\hline $\begin{array}{c}\text { SDB with } \\
\text { CHF }\end{array}$ & $67.38 \pm 17.78 \mathrm{~b}$ & $57.75 \pm 13.38 \mathrm{~b}$ & $32.88 \pm 14.27 \mathrm{~b}$ & $27.38 \pm 10.49 \mathrm{~b}$ & $9.0 \pm 7.11 \mathrm{~b}$ \\
\hline
\end{tabular}

Abbreviations: SDNN (ms) - standard deviation of the NN intervals in 24 hours; SDANN (ms) - standard deviation of the average $\mathrm{NN}$ interval calculated over short periods (5 minutes); SDNN index (ms) - mean of the 5-minutes standard deviation of the NN interval calculated over 24 hours; rMSSD (ms) - square root of the mean squared differences of successive NN intervals; pNN50 (\%) - percentage of adjacent NN intervals differing more than 50 milliseconds on duration. Values followed by different letters in the column differ statistically in ANOVA analysis $(\mathrm{P}<0.05)$.

Although some analyzed variables had shown $\mathrm{P}<0.05$, Pearson coefficient analysis identified no correlation between the HRV indices and the supraventricular or ventricular arrhythmias recorded by 24-hour Holter monitoring, as demonstrated by the low values of the coefficient (Table 2).

Table 2. Pearson coefficient correlation ( $\mathrm{r}$ value) of heart rate variability indices and arrhythmias recorded in 24 hours of Holter monitoring of the studied Boxer dogs $(n=69)$

\begin{tabular}{lccccc}
\hline \multicolumn{1}{c}{ Arrhythmias on Holter } & SDNN & SDANN & SDNNi & rMSSD & pNN50 \\
\hline Number of isolated APC & -0.135 & -0.092 & -0.245 & -0.211 & -0.196 \\
Number of isolated VPC & -0.252 & -0.246 & -0.33 & -0.158 & -0.101 \\
Paired VPC & -0.157 & -0.149 & -0.18 & -0.121 & -0.118 \\
Ventricular bigeminism & -0.189 & -0.179 & -0.263 & -0.141 & -0.098 \\
Non-sustained VT & -0.146 & -0.122 & -0.214 & -0.131 & -0.124 \\
\hline
\end{tabular}

Abbreviations: SDNN (ms) - standard deviation of the NN intervals in 24 hours; SDANN (ms) - standard deviation of the average $\mathrm{NN}$ interval calculated over short periods (5 minutes); SDNN index (ms) - mean of the 5-minutes standard deviation of the NN interval calculated over 24 hours; rMSSD (ms) - square root of the mean squared differences of successive NN intervals; pNN50 (\%) - percentage of adjacent $\mathrm{NN}$ intervals differing more than 50 milliseconds on duration; APC - atrial premature complex; VPC - ventricular premature complex; VT - ventricular tachycardia.

The Cox multivariate proportional hazards model showed no influence of age, sex, weight or the HRV indices on the survival of animals affected by ARVC, as there was no relation between these covariates and death of cardiac origin $(\mathrm{P}>0.05)$. However, this statistical method showed that the presence of clinical manifestations such as syncope with or without clinical signs of heart failure $(p=0.0007 ; \mathrm{HR}=26.3897$ and $\mathrm{p}=$ $0.0087 ; \mathrm{HR}=5.6219$, respectively) and the number of ventricular tachycardia (VT) episodes $(p=0.0005 ; \mathrm{HR}=1.0041)$ detected by Holter examination were covariates related with the survival of animals affected by ARVC, as illustrated in Table 3. 
Valor prognóstico da variabilidade...

Table 3. Cox regression analysis of the influence of covariates on survival of Boxer dogs studied (Overall model fit: chi-squared $=39.292$ with $\mathrm{DF}=5$ and $\mathrm{P}<0.0001 ; \mathrm{n}=66$ )

\begin{tabular}{|c|c|c|c|c|c|}
\hline Covariate & $\mathrm{b}$ & $\begin{array}{r}\text { Standard } \\
\text { Error }\end{array}$ & $P$ & $\begin{array}{r}\text { Hazard Ratio } \\
\text { (HR) }\end{array}$ & $95 \% \mathrm{CI}$ of $\mathrm{HR}$ \\
\hline $\begin{array}{l}\text { Symptoms of heart } \\
\text { failure and Syncope }\end{array}$ & 3.2730 & 0.9613 & 0.0007 & 26.3897 & 4.0489 to 171.9989 \\
\hline $\begin{array}{l}\text { Presence of } \\
\text { syncope }\end{array}$ & 1.7267 & 0.6580 & 0.0087 & 5.6219 & 1.5583 to 20.2828 \\
\hline VT & 0.004120 & 0.001183 & 0.0005 & 1.0041 & 1.0018 to 1.0064 \\
\hline
\end{tabular}

\section{DISCUSSION}

Since ARVC is a genetic disease that often causes sudden death in Boxer dogs, establishing prognostic factors for this disease is of great importance for staging and counseling for breeding of affected dogs.

In the present study, the prognostic value of some variables in Boxer ARVC was evaluated, including indices of HRV and arrhythmias recorded by Holter. The results showed that HRV indices are not good predictors of death of cardiac origin in Boxer dogs with this cardiomyopathy, as there was no statistical correlation between these indices and sudden death or death from congestive heart failure. In humans, the decrease in HRV due to increases of the sympathetic tone predisposes the subject to the development of fatal ventricular arrhythmias, particularly after a myocardial infarction (Pecyna 2006). Moreover, this parameter is used as a predictor of sudden death in patients with CHF and ventricular arrhythmias (Malik et al. 1996, Spier and Meurs 2004a). A study was conducted to assess HRV in humans affected by ARVC, and a decrease in the values of these indices in patients more severely affected by the disease has been found, suggesting an important role for the autonomic nervous system in the genesis of these arrhythmias (Folino et al. 2002). Some degree of involvement of sympathetic stimulation in the development of ventricular arrhythmias in Boxer dogs with ARVC was also found in a study (Scansen et al. 2009). Heart rate variability has also been studied in Boxer dogs with ARVC to clarify the role of the autonomic nervous system in the genesis of ventricular arrhythmias found in this disease; however, these studies did not find significant differences in the HRV indices of affected animals without CHF when compared to control dogs (Spier \& Meurs 2004a). In agreement with these studies and in contrast to what is observed in people affected by ARVC, the present study also failed to observe a decrease in the HRV indices of Boxer dogs with ARVC without CHF when compared to Boxer dogs in the control group. Additionally, the statistical analysis did not find any correlation between the HRV indices and the number or severity of ventricular arrhythmias registered by Holter monitoring. However, to suggest that this lack of correlation means that ventricular arrhythmias in Boxer ARVC are not modulated by autonomic tone, as the human form of this disease, the HRV immediately before the occurrence of dangerous ventricular arrhythmias would need to be analyzed. Although the overall HRV was not diminished in ARVC Boxer dogs without CHF in this study, we cannot confirm whether autonomic modulation influenced the occurrence of ventricular arrhythmias in these dogs because we did not perform such an analysis immediately prior to the arrhythmic event.

Using a Cox regression model, no detectable influence of $\mathrm{HRV}$ indices on the deaths of cardiac origin of Boxer dogs with ARVC was found in this study, suggesting that such variables are poor prognostic indicators for this disease in dogs. On the other hand, the presence of clinical signs of heart failure and syncope and the number of VT episodes registered during the Holter examination were correlated with the survival of the affected animals. Although the age of the animal at diagnosis has been statistically significant at univariate Cox analysis, it didn't show any significance in the multivariate analysis, characterizing age only as a risk factor and not as a prognostic factor. In fact, Boxer ARVC is a disease of adult onset that 
results in worsening of the degree of ventricular arrhythmia that is proportional with the age of affected animals (Moïse, 1999, Baumwart et al., 2005). Thus, older animals are expected to exhibit a greater tendency for sudden death due to the higher number or severity of ventricular arrhythmias or CHF secondary to ventricular dilation and systolic dysfunction (Palermo et al., 2011). Similar results were obtained in a recent study that demonstrated that the presence of ventricular tachycardia and advanced age were independent predictors of cardiac mortality on Boxer ARVC (Mötsküla et al., 2013).

Although many researchers did not find differences in the HRV indices of Boxer dogs with ARVC without CHF compared to control dogs, a reduction of these indices was found in animals with the more severe form of the disease, which is associated with systolic dysfunction, ventricular dilation and heart failure (Spier and Meurs, 2004a). Similarly, this study also showed a statistically significant difference in the HRV indices of ARVC Boxer dogs with systolic dysfunction and $\mathrm{CHF}$ (SDB with $\mathrm{CHF}$ group), compared to Boxer control dogs (CB group) and those with systolic dysfunction but without CHF (SDB without CHF group). This observation is supported by the fact that heart failure is associated with sympathetic activation and parasympathetic attenuation with high levels of circulating catecholamines, leading to a significant reduction in HRV that is inversely proportional to the levels of norepinephrine (Malik et al., 1996, Spier and Meurs, 2004a).

Several limitations may have affected the results of this study. The major limitations were the limited number of animals enrolled in each group and the lack of performing an abdominal ultrasound in all the animals enrolled in the study to assess the presence of splenic masses that could lead to ventricular arrhythmias. Another important limitation was our unavailability to perform a striatin genetic mutation test in the studied Boxer dogs; the application of this test might have more precisely elucidated which animals were truly affected by Boxer ARVC. The use of an arbitrary cutoff value of VPCs on a single Holter examination for the classification of dogs as having ARVC may have led to misclassification of some patients, although the values used in this study were based on previous studies (Stern et al., 2010, Meurs et al., 2014).
The fact that the mean values of SDNN in the control Boxer $\operatorname{dog} s$ of this study was considerably lower than that obtained by other researchers (Spier and Meurs 2004a) suggests that the dogs used as controls might have had an occult form of the disease, consequently reducing their HRV. In fact, the median age of this group was 5.6 years and it is known that ARVC is an adult-onset disease; thus, without striatin tests or several Holter evaluations from the same animal, since a large daily variability may occur in the number of arrhythmias recorded by Holter examination (Spier and Meurs, 2004b), we cannot confirm whether these Boxer dogs used as controls were truly unaffected. Although at the time of data acquisition none of the animals was receiving antiarrhythmics, some of them subsequently began receiving amiodarone as antiarrhythmic medication, and this treatment may have interfered in survival analysis of affected animals, since antiarrhythmic drugs may have proarrhythmic effects, worsening the existing arrhythmia and leading to sudden death.

\section{CONCLUSIONS}

Heart rate variability indices are poor prognostic factors for mortality in Boxer dogs affected by ARVC, but the presence of syncope with or without symptoms of congestive heart failure and the number of VT episodes detected by Holter examination are good prognostic indicators for Boxers with ARVC, as these variables showed a significant correlation with the survival rate of the affected dogs.

\section{REFERENCES}

BASSO, C.; FOX, P.R.; MEURS, K.M. et al. Arrhythmogenic right ventricular cardiomyopathy causing sudden cardiac death in Boxer dogs: a new animal model of human disease. Circulation, v.109, p.1180-1185, 2004.

BAUMWART, R.D.; MEURS, K.M.; ATKINS, C.E. et al. Clinical, echocardiographic and electrocardiographic abnormalities in Boxers with cardiomyopathy and left ventricular systolic dysfunction: 48 cases (1985-2003). J. Am. Vet. Med. Assoc., v.226, p.1102-1104, 2005.

BRIGHT, J.M.; McENTEE, M. Isolated right ventricular cardiomyopathy in a dog. J. Am. Vet. Med. Assoc., v.207, p.64-66, 1995. 
CORRADO, D.; FONTAINE, G.; MARCUS, F.I. et al. Arrhythmogenic right ventricular dysplasia/cardiomyopathy: need for an international registry. Circulation, v.101, p.1-6, 2000.

DUKES-McEWAN, J.; BORGARELLI, M.; TIDHOLM, A. et al. Proposed guidelines for the diagnosis of canine idiopathic dilated cardiomyopathy. J. Vet. Cardiol., v.5, p.7-19, 2003.

FOLINO, A.F.; BUJA, G.; BAUCE, B. et al. Heart rate variability in arrhythmogenic right ventricular cardiomyopathy - correlation with clinical and prognostic features. Pacing Clin. Electrophysiol., v.25, p.1285-1292, 2002.

HARPSTER, N.K. Boxer cardiomyopathy. In: KIRK, R.W. Current veterinary therapy VIII. Philadelphia: Saunders Company, 1983. p.329-337.

MALIK, J.M.; BIGGER, T.; CAMM, A.J. et al. Heart rate variability: standards of measurement, physiological interpretation, and clinical use. Eur. Heart J., v.17, p.354-381, 1996.

MEURS, K.M. Boxer dog cardiomyopathy: an update. Vet. Clin. N. Am. Small Anim. Pract., v.34, p.12351244, 2004.

MEURS, K.M.; EDERER, M.M.; STERN， J.A. Desmosomal gene evaluation in Boxers with arrhythmogenic right ventricular cardiomyopathy. $\mathrm{Am}$. J. Vet. Res., v.68, p.1338-1341, 2007.

MEURS, K.M.; MAUCELI, E.; LAHMERS, S. et al. Genome-wide association identifies a deletion in the 3' untranslated region of Striatin in a canine model of arrhythmogenic right ventricular cardiomyopathy. Hum. Genet., v.128, p.315-324, 2010.

MEURS, K.M.; SPIER, A.W.; MILLER, M.W. et al. Familial ventricular arrhythmias in Boxers. J. Vet. Intern. Med., v.13, p.437-439, 1999.

MEURS, K.M.; STERN, J.A.; REINA-DORESTE, Y. et al. Natural history of arrhythmogenic right ventricular cardiomyopathy in the Boxer dog: a prospective study. J. Vet. Intern. Med., v.28, p.12141220,2014

MOISE, N.S. Diagnosis and management of canine arrhythmias. In: FOX, P.R.; SISSON, D.; MOISE, N.S. Textbook of canine and feline cardiology. 2.ed. Philadelphia: Saunders Company, 1999. p.331-399.

MÖTSKÜLA, P.F.; LINNEY, C.; PALERMO, V. et al. Prognostic value of 24-hour ambulatory ECG (Holter) monitoring in Boxer dogs. J. Vet. Intern. Med., v.27, p.904-912, 2013.
OXFORD, E.M.; DANKO, C.G.; KOMREICH, B.G. et al. Ultrastructural changes in cardiac myocytes from Boxer dogs with arrhythmogenic right ventricular cardiomyopathy. J. Vet. Cardiol., v.13, p.101-113, 2011.

OXFORD, E.M.; EVERITT, M.; COOMBS, W. et al. Molecular composition of the intercalated disc in a spontaneous canine animal model of arrhythmogenic right ventricular dysplasia/cardiomyopathy. Heart Rhythm, v.4, p.1196-1205, 2007.

PALERMO, V.; JOHNSON, M.J.S.; SALA, E. et al. Cardiomyopathy in Boxer dogs: a retrospective study of the clinical presentation, diagnostic findings and survival. J. Vet. Cardiol., v.13, p.45-55, 2011.

PECYNA, M.B. The level of intelligence and heart rate variability in men after myocardial infarction. $J$. Physiol. Pharmacol., v.57, Suppl.4, p.283-287, 2006.

SCANSEN, B.A.; MEURS, K.M.; SPIER, A.W. et al. Temporal variability of ventricular arrhythmias in Boxer dogs with arrhythmogenic right ventricular cardiomyopathy. J. Vet. Intern. Med., v.23, p.10201024,2009 .

SCHOBER, K.; FUENTES, V.L.; BAADE, H.; OECHTERING, G. Echokardiographische referenzwerte beim Boxer. Tierärztl. Praxis, v.30, p.417-426, 2002.

SISSON, D.; O'GRADY, M.R.; CALVERT, C.A. Myocardial diseases of dogs. In: FOX, P.R.; SISSON, D.; MOISE, N.S. Textbook of canine and feline cardiology. 2.ed. Philadelphia: Saunders Company, 1999. p.581-619.

SPIER, A.W.; MEURS, K.M. Assessment of heart rate variability in Boxers with arrhythmogenic right ventricular cardiomyopathy. J. Am. Vet. Med. Assoc., v.224, p.534-537, 2004a.

SPIER, A.W.; MEURS, K.M. Evaluation of spontaneous variability in the frequency of ventricular arrhythmias in Boxers with arrhythmogenic right ventricular cardiomyopathy. J. Am. Vet. Med. Assoc., v.224, p.538-541, 2004b.

STERN, J.A.; MEURS, K.M.; SPIER, A.W. et al. Ambulatory electrocardiographic evaluation of clinically normal adult Boxers. J. Am. Vet. Med. Assoc., v.236, p.430-433, 2010.

VANDERLEI, L.C.M.; PASTRE, C.M.; HOSHI, R.A. et al. Noções básicas de variabilidade da frequência cardíaca e sua aplicabilidade clínica. Rev. Bras. Circ. Cardiovasc., v.24, p.205-217, 2009. 